\title{
Association between CA repeat polymorphism in IGF1 gene promoter and colorectal cancer risk in a native Chinese population
}

\author{
X. L. CHAO ${ }^{1,2}$, L. L. WANG ${ }^{1}$, R. LIU $2, *$ Y. LI' ${ }^{1}$ X. J. ZHOU ${ }^{1}$ \\ ${ }^{1}$ Graduate School of Tianjin Medical University, Tianjin, China; ${ }^{2}$ Department of Clinical Laboratory, Tianjin Union Medical Center, Tianjin, \\ China
}

${ }^{*}$ Correspondence: $\operatorname{lr} 522018 @ 163 . c o m$

Received January 17, 2019 / Accepted April 16, 2019

\begin{abstract}
Insulin-like growth factor 1 (IGF1) is implicated in normal cell growth. It has been reported that IGF1 has a mitogenic and anti-apoptotic effect on colorectal cancer cells. However, results of studies on the association between cytosine-adenine (CA) repeat polymorphism in IGF1 gene promoter and colorectal cancer (CRC) risk are inconsistent. We aimed to evaluate the association between CA repeat polymorphism and CRC risk, as well as the relationship with the clinicopathological characteristics of CRC and circulating IGF1 level in a native Chinese population. There were 734 participants who were native Chinese in this case-control study, including $367 \mathrm{CRC}$ cases and 367 age- and sex-matched controls. CA repeat polymorphism was genotyped by PCR and fragment analysis. Odds ratios (ORs) and 95\% confidence intervals (CIs) were evaluated by unconditional logistic regression analysis. Circulating level of IGF1 in cases was significantly higher than that in controls $(\mathrm{p}=0.002)$, particularly in males. Less than 38 CA repeats were associated with decreased CRC risk after adjusting for age and sex ( 37 versus 38 CA repeats: $O R=0.45 ; 95 \% \mathrm{CI}=0.26-0.78$ ), especially in males. (CA) $18 / 19$ genotype showed approximately half reduced CRC risk comparing to $(\mathrm{CA}) 19 / 19$ genotype $(\mathrm{OR}=0.46 ; 95 \% \mathrm{CI}=0.25-0.85)$. There was a significant association between the sum of CA repeats and degree of differentiation of CRC $(\mathrm{p}=0.044)$. We observed a trend that circulating level of IGF1 in individuals with CA $\leq 38$ repeats was lower than that in individuals with CA $>38$ repeats with a borderline statistical significance in overall and males. In conclusion, our findings support the possible role of CA repeat polymorphism in CRC risk.
\end{abstract}

Key words: insulin-like growth factor 1, polymorphism, CA repeat, colorectal cancer

Colorectal cancer (CRC) has become a global burden due to its high incidence and mortality worldwide. It has been recently reported an estimation of over 1.8 million new CRC cases and 881000 deaths in 2018 worldwide. CRC ranks third for overall incidence and second for mortality [1]. However, the age-standardized incidence rate of CRC has been reported to rise from 16.1 to 17.5 per 100000 from 2010 to 2014 in China, while the age-standardized mortality rate fluctuates between 7.6 and 7.9 per 100000 [2]. It has been known that CRC is a complicated disease as tumors can occur in various subsites of colorectum and risk factors are different between males and females, which is totally distinct from breast cancer and prostate cancer. Both environmental and genetic factors may contribute to carcinogenesis of colorectum. Insulin-like growth factor 1 (IGF1) may be one of the factors.

IGF1, a polypeptide with 70 amino acids, is a component of IGF1 pathway important for the regulation of cell growth, differentiation and survival [3]. In vitro studies have demonstrated that IGF1 is a potent mitogenic factor for colorectal carcinoma cell lines, as well as an important anti-apoptotic factor in colon cancer cells $[4,5]$. As it is considered as a regulator of cell proliferation and apoptosis, IGF1 may be implicated in carcinogenesis. A meta-analysis has shown that higher IGF1 circulating level is significantly associated with increased overall cancer risk, the association is particularly obvious in CRC, premenopausal breast cancer and prostate cancer [6]. However, circulating level of IGF1 is influenced by many factors. Both lifestyle and genetic factors are related to circulating level of IGF1 [7-9]. Twin study has indicated that $38 \%$ variation in circulating level of IGF1 derives from genetic effects [9]. A known genetic polymorphism, cytosineadenine (CA) repeat polymorphism in IGF1 gene promoter has become the focus of a number of studies.

CA repeat polymorphism with variable length composed of multiple cytosine-adenine dinucleotides is located in the 
promoter region 969 bp upstream from transcription start site of the IGF1 gene, which has been proved to be related to serum IGF1 level in an early study [10]. The range of CA repeat numbers varies in different populations, generally the most common CA repeat number is 19 [11-13]. Although the results are controversial, IGF1 CA repeat polymorphism has been extensively evaluated in relation to the risk of various cancers in many studies, including breast cancer [12-15], prostate cancer [16-19], and CRC [11, 20-24]. Some studies have demonstrated that CA repeat polymorphism in the promoter of IGF1 gene is associated with the CRC risk [11, $21,23,24]$, however, some studies have indicated that there is no such association $[20,22]$. The role of CA repeat polymorphism in the carcinogenesis of CRC remains ambiguous. Due to inconsistent results in different populations and races, we suppose that the association between CA repeat polymorphism and CRC risk may be related to the characteristics of specific population and ethnicity or race. To our knowledge, there has been no report on the association between $\mathrm{CA}$ repeat polymorphism and $\mathrm{CRC}$ risk in a native Chinese population up to now, only a Singapore Chinese population has been analyzed [11]. Furthermore, the classification methods of CA repeat polymorphism are not uniform when analyzed in different studies, which may affect the results.

Considering the high incidence of CRC worldwide, growing incidence of CRC in China and inconsistent view on the role of CA repeat polymorphism in CRC risk, we investigate the association between CA repeat polymorphism and CRC risk, as well as the relation to the clinicopathological characteristics of CRC in a native Chinese population. In addition, we evaluate the relationship between CA repeat polymorphism and circulating level of IGF1 in this study.

\section{Patients and methods}

Study population. Subjects were recruited from Tianjin Union Medical Center between May 2011 and November 2015, with a case-control design. All subjects were native Chinese from the same ethnicity, Han Chinese. Cases were ascertained by professional pathologists and were at first diagnosis of colorectal cancer confirmed historically. All cases were excluded of diabetes and other malignant disease. There were 367 cases diagnosed with colon cancer or rectal cancer included. The pathological characteristics (Dukes stage, degree of differentiation, tumor location) of colorectal cancer were directly extracted from the Pathological Report of patients. Controls matched to cases by age and sex were selected from physical examination population. We selected 367 controls at the exclusion of diabetes, cardiovascular and malignant disease by laboratory and imaging tests. Total subjects included in this study provided the informed consent. Our study was approved by the Academic Committees of Tianjin Union Medical Center.

Blood specimens and laboratory assays. Venous blood samples were drawn into coagulant tubes from all subjects in the early morning after fasting for 8 hours. Chemiluminescence assay with the reagent kit from Siemens was used to determine serum levels of IGF1 by Immulite 2000 (Siemens, Germany). In addition, $3 \mathrm{ml}$ of whole blood was drawn into EDTA anticoagulant tube from every subject, then the blood samples were stored at $-80^{\circ} \mathrm{C}$ until experimental use.

DNA extraction. Genomic DNA was extracted from blood leukocytes using TIANamp Blood DNA Midi Kit (Tiangen Biotech, Beijing, China), referring to instructions of the manufacturer. The extracted DNA samples were stored at $-80^{\circ} \mathrm{C}$ for further analysis.

Genotyping. IGF1 CA repeat polymorphism was measured by PCR and fragment analysis using ABI-3730XL DNA Sequencer (Applied Biosystems, Foster City, CA). PCR amplification was performed using the primers, 5'-AGAAAACACACTCTGGCACAC-3' and 5'-GCAAAGACTCTGCCGAGCTG-3' (Invitrogen, Shanghai, China). The 5' end of the forward primer was labeled with FAM for fluorescence detection. A total volume of $50 \mu \mathrm{l}$ of the PCR reaction mixture consisted of $10 \mathrm{ng}$ DNA, $2 \mu \mathrm{l}$ each of the $5 \mu \mathrm{M}$ primers, $4 \mu \mathrm{l}$ $2 \mathrm{mM}$ dNTPs, $5 \mu \mathrm{l}$ 10x PCR buffer, $1.6 \mu \mathrm{l} 50 \mathrm{mM} \mathrm{MgCl}_{2}$ and 1.5U Platinum ${ }^{\circledast}$ Taq DNA polymerase (Invitrogen, Shanghai, China). The amplification conditions were: 1 cycle of $5 \mathrm{~min}$ at $95^{\circ} \mathrm{C}$ followed by 35 thermal cycles constituting of $30 \mathrm{~s}$ at $95^{\circ} \mathrm{C}$ (denaturation), $30 \mathrm{~s}$ at $60^{\circ} \mathrm{C}$ (annealing) and $30 \mathrm{~s}$ at $72^{\circ} \mathrm{C}$ (extension), and a final extension step at $72^{\circ} \mathrm{C}$ for 5 min. GeneScan 3.0 and GeneMapper software (Applied Biosystems) were used to determine the length of amplified fragments.

Statistical analysis. For descriptive characteristics of cases and controls, categorical variables were expressed as numbers (percentage), and were evaluated using chi-square test. Continuous normal distribution variables were given as mean \pm standard deviation and were analyzed by independent sample t-test. Allele frequencies of CA repeat polymorphism between cases and controls were compared by chi-square test. To estimate the relation to CRC risk, CA repeat polymorphism was classified as three groups: i) group 1: classical group as analyzed in most studies, (CA)19 repeat status in both alleles, homozygous (CA)19/19 repeat, heterozygous CA19/non-19, homozygous (CA)non-19/non-19; ii) group 2: the sum of CA repeats in both alleles according to Simons et al. [24], $\mathrm{CA} \leq 36,37,38,39$ and $\geq 40$ repeats; iii) group 3: four of the most common genotypes, (CA) $19 / 19,19 / 21,18 / 19$ and $18 / 21$ in both of cases and controls. Odds ratio (OR) with $95 \%$ confidence intervals (95\% CI) was determined by unconditional logistic regression models adjusted for age and sex to evaluate the association between $\mathrm{CA}$ repeat polymorphism and $\mathrm{CRC}$ risk. The relationship between CA repeat polymorphism and clinicopathologic characteristics of CRC was assessed by chi-square test according to group 1 as above mentioned, the sum of CA repeats $\leq 38$ and $>38$ in both alleles respectively. The relationship between CA repeat polymorphism and circulating level of IGF1 was evaluated via independent sample t-test, which 
classified as the presence of (CA)19 allele and the absence of (CA)19 allele(non-19), the sum of CA repeats $\leq 38$ and $>38$ in both alleles. SPSS 20.0 software was used for all statistical analyses. A two-side $\mathrm{p}<0.05$ was considered to indicate a statistically significant difference.

\section{Results}

Descriptive characteristics of cases and controls are shown in Table 1. A total of 367 cases and 367 controls were included in this study. Cases did not differ obviously from controls for age and sex as they were matched. However, circulating levels of IGF1 in cases were significantly higher compared with controls for overall individuals, nevertheless, the difference was evident only in males but not females after stratification by sex. There were 120 patients with colon cancers and 247 patients with rectal cancers. 211 cases were in stage A and B for Dukes stage, while 156 cases were in stage $\mathrm{C}$ and $\mathrm{D}$. The dominant degree of differentiation was moderate differentiation in cases, the following was well (high/high-moderate) differentiation, while the proportion of poor (moderate-low/low) differentiation was the smallest within the cases.

The frequency distribution of CA repeat allele in cases and controls is listed in Table 2. The range of CA repeat in cases was different from controls. The (CA)19 repeat allele was the most frequent allele in both cases and controls for total subjects, males and females. $36.2 \%$ of cases and $33.9 \%$ of controls carried the (CA)19 allele in total subjects. There was no significant difference in frequency distribution of CA repeat allele between cases and controls for total subjects $(\mathrm{p}=0.199)$, males $(\mathrm{p}=0.175)$ and females $(\mathrm{p}=0.706)$.

The association between CA repeat polymorphism and CRC risk is shown in Table 3. The (CA) 19 repeat genotype was not associated with CRC risk in group 1. Individuals with $37 \mathrm{CA}$ repeats for the sum of CA repeats in both alleles had approximately half CRC risk comparing to individuals with $38 \mathrm{CA}$ repeats after adjusting for age and sex in group 2 $(\mathrm{OR}=0.45 ; 95 \% \mathrm{CI}=0.26-0.78)$. There was a borderline statistically significant association of decreased CRC risk with $\leq 36$ CA repeats. However, there was no significant association between $>38$ CA repeats and CRC risk. Comparing to (CA)19/19 genotype, (CA)18/19 but not (CA)19/21 or (CA)18/21 genotype was significantly associated with approximately half reduced CRC risk in group $3(\mathrm{OR}=0.46$; $95 \% \mathrm{CI}=0.25-0.85)$. Then the relation of CA repeat polymorphism with CRC risk evaluated after stratification by sex is shown in Table 4 (considering the sample size was small after classification, we classified the sum of CA repeats as $<38$ repeats, 38 repeats and $>38$ repeats). The uncorrelation between (CA) 19 repeat polymorphism and CRC risk did not change after stratification by sex. Nevertheless, carrying $<38$ CA repeats but not $>38$ CA repeats was significantly associated with reduced risk of $\mathrm{CRC}$, comparing to carrying $38 \mathrm{CA}$ repeats in males $(\mathrm{OR}=0.48 ; 95 \% \mathrm{CI}=0.28-0.81)$, while there was no correlation of $<38 \mathrm{CA}$ repeats with decreased risk of $\mathrm{CRC}$ in females.

The association between $\mathrm{CA}$ repeat polymorphism and clinicopathologic characteristics of CRC in 367 cases (Table 5 and Table 6). (CA) 19 repeat polymorphism was not related to clinicopathologic characteristics of CRC. Nevertheless, the sum of CA repeats was associated with degree

Table 1. Descriptive characteristics of study participants.

\begin{tabular}{lccc}
\hline Characteristics & $\begin{array}{c}\text { Cases } \\
(\mathbf{n}=\mathbf{3 6 7})\end{array}$ & $\begin{array}{c}\text { Controls } \\
(\mathbf{n}=\mathbf{3 6 7})\end{array}$ & p-value \\
\hline Age (y) & $65.80 \pm 9.53$ & $65.80 \pm 9.39$ & $0.975^{\mathrm{a}}$ \\
Sex & & & $0.449^{\mathrm{b}}$ \\
$\quad$ Male & $219(59.7)$ & $229(62.4)$ & \\
$\quad$ Female & $148(40.3)$ & $138(37.6)$ & \\
IGF1 (ng/ml) & & & \\
$\quad$ Overall & $146.91 \pm 69.55$ & $132.88 \pm 46.96$ & $0.002^{\mathrm{a}}$ \\
$\quad$ Male & $159.42 \pm 69.46$ & $138.65 \pm 45.51$ & $<0.010^{\mathrm{a}}$ \\
$\quad$ Female & $128.41 \pm 65.65$ & $122.72 \pm 47.93$ & $0.413^{\mathrm{a}}$ \\
Tumor location & & - & - \\
$\quad$ Colon & $120(32.7)$ & & \\
$\quad$ Rectum & $247(67.3)$ & & - \\
Dukes stage & & - & \\
$\quad$ A+B & $211(57.5)$ & & \\
$\quad$ C+D & $156(42.5)$ & & \\
Degree of differentiation & & & \\
$\quad$ High/High-moderate & $94(25.6)$ & & \\
$\quad$ Moderate & $210(57.2)$ & & \\
$\quad$ Moderate-low/Low & $63(17.2)$ & & \\
\hline
\end{tabular}

abased on independent sample t-test, bbased on chi-square test.

Table 2. Distribution of IGF1 CA repeat allele frequencies in study population.

\begin{tabular}{|c|c|c|c|c|c|c|}
\hline \multirow{2}{*}{ CA repeats } & \multicolumn{2}{|c|}{ Total subjects } & \multicolumn{2}{|c|}{ Male } & \multicolumn{2}{|c|}{ Female } \\
\hline & Cases (\%) & Controls (\%) & Cases (\%) & Controls (\%) & Cases (\%) & Controls (\%) \\
\hline$\leq 17$ & $71(9.7)$ & $89(12.1)$ & $38(8.7)$ & $55(12.0)$ & $33(11.1)$ & $34(12.3)$ \\
\hline 18 & $136(18.5)$ & 145 (19.8) & $80(18.3)$ & $97(21.2)$ & $56(18.9)$ & $48(17.4)$ \\
\hline 19 & $266(36.2)$ & $249(33.9)$ & $156(35.6)$ & $148(32.3)$ & $110(37.2)$ & $101(36.6)$ \\
\hline 20 & $81(11.0)$ & $61(8.3)$ & 49 (11.2) & $40(8.7)$ & $32(10.8)$ & $21(7.6)$ \\
\hline 21 & $154(21.0)$ & $154(21.0)$ & $100(22.8)$ & $94(20.5)$ & $54(18.2)$ & $60(21.7)$ \\
\hline$\geq 22$ & $26(3.5)$ & $36(4.9)$ & $15(3.4)$ & $24(5.2)$ & $11(3.7)$ & $12(4.3)$ \\
\hline Range & $11-24$ & $13-26$ & $11-24$ & $13-26$ & $15-24$ & $14-24$ \\
\hline
\end{tabular}


of differentiation of CRC ( $\mathrm{p}=0.044)$, the percentage of poor (moderate-low/low) differentiation in patients carrying CA $\leq 38$ repeats was higher than that in patients carrying CA $>38$ repeats (20.5\% versus $13.4 \%$ ), but the percentage of well (high/high-moderate) differentiation was opposite. There was no significant association between sex, tumor location, Dukes stage of CRC and the sum of CA repeats.

The association between IGF1 genotype and circulating level of IGF1 in 367 controls (Table 7). There was no significant relationship between (CA)19 repeat polymorphism and circulating level of IGF1. Although there was just a borderline statistical significance, we found a trend that circulating level of IGF1 in individuals with CA $\leq 38$ repeats was lower than that in individuals with CA $>38$ repeats in overall and males, but not females.

Table 3. ORs and 95\% CIs for the IGF1 CA repeat polymorphism and CRC risk

\begin{tabular}{lccc}
\hline CA repeat groups & $\begin{array}{c}\text { Cases/Controls } \\
(\mathbf{n}=\mathbf{3 6 7} / \mathbf{n}=\mathbf{3 6 7})\end{array}$ & $\mathbf{O R}^{\mathrm{a}}(\mathbf{9 5} \% \mathbf{C I})$ & $\mathbf{p}$-value \\
\hline Group 1 & & & \\
(CA)19/19 & $65 / 50$ & $1.00($ reference $)$ & \\
(CA)19/non-19 & $136 / 148$ & $0.71(0.46-1.10)$ & 0.126 \\
$\quad$ (CA)non-19/non-19 & $166 / 169$ & $0.76(0.50-1.17)$ & 0.209 \\
Group 2 & & & \\
$\leq 36$ repeats & $64 / 73$ & $0.66(0.42-1.04)$ & 0.075 \\
37 repeats & $30 / 50$ & $0.45(0.26-0.78)$ & 0.004 \\
38 repeats & $101 / 76$ & $1.00($ reference $)$ & \\
39 repeats & $57 / 48$ & $0.92(0.56-1.50)$ & 0.734 \\
$\geq 40$ repeats & $115 / 120$ & $0.73(0.49-1.08)$ & 0.110 \\
Group 3 & & & \\
(CA)19/19 & $65 / 50$ & $1.00($ reference $)$ & \\
(CA)19/21 & $55 / 47$ & $0.90(0.53-1.54)$ & 0.701 \\
(CA)18/19 & $25 / 43$ & $0.46(0.25-0.85)$ & 0.013 \\
(CA)18/21 & $35 / 31$ & $0.89(0.48-1.64)$ & 0.702 \\
\hline
\end{tabular}

\section{Discussion}

Our results have shown an association between the sum of CA repeats polymorphism in the promoter region of IGF1 gene and $\mathrm{CRC}$ risk in a native Chinese population. We found the protective effect of $<38$ CA repeats for CRC risk, particularly in males. While a Netherlands Cohort Study indicated carrying $<38 \mathrm{CA}$ repeats but not $>38 \mathrm{CA}$ repeats was related to half decreased CRC risk ( $\leq 36$ versus 38 repeats: $\mathrm{HR}=0.44$; 95\% CI=0.33-0.58; p-trend <0.001) in females but not males [24]. It is possible that the association between CRC risk and the sum of CA repeats may be influenced by sex for different populations. Further studies are needed to verify the role of $<38$ CA repeats in CRC risk in other populations, and whether their association is affected by sex. In contrast, it has been reported that $<38 \mathrm{CA}$ repeats was not significantly associated with breast cancer risk in either pre- or postmenopausal women using $\geq 38 \mathrm{CA}$ repeats as reference in a case-control study among Arab Omani women [25], which indicated there was no protective effect of $<38 \mathrm{CA}$ repeats for breast cancer. It implies that the role of the sum of CA repeats in cancer risk may vary with the type of cancer. But considering there has been a few studies on the association between $<38$ CA repeats and cancer risk, it needs to be further confirmed in more studies.

There was a trend for $\leq 38 \mathrm{CA}$ repeats presenting lower circulating level of IGF1 than $>38$ CA repeats in controls in our study. A meta-analysis demonstrated that higher circulating level of IGF1 significantly increased overall cancer risk, including CRC risk [6]. Similarly, circulating level of IGF1 in patients was significantly higher than that in controls in our study, especially in males. It seems that the association between the sum of CA repeats and CRC risk depends on the effect of the sum of CA repeats in IGF1 gene on circulating level of IGF1. Nevertheless, due to the lack of convincing evidence, it remains uncertain whether the sum of CA repeats

adjusted for age and sex

Table 4. ORs and 95\% CIs for the IGF1 CA repeat polymorphism and CRC risk stratified by sex.

\begin{tabular}{|c|c|c|c|c|c|c|}
\hline \multirow[b]{2}{*}{ CA repeat groups } & \multicolumn{3}{|c|}{ Male } & \multicolumn{3}{|c|}{ Female } \\
\hline & $\begin{array}{l}\text { Cases/Controls } \\
(n=229 / n=219)\end{array}$ & $\mathrm{OR}^{\mathrm{a}}(95 \% \mathrm{CI})$ & p-value & $\begin{array}{l}\text { Cases/Controls } \\
(n=138 / n=148)\end{array}$ & $\mathrm{OR}^{\mathrm{a}}(95 \% \mathrm{CI})$ & p-value \\
\hline \multicolumn{7}{|l|}{ Group 1} \\
\hline (CA)19/19 & $28 / 36$ & 1.00 (reference) & & $22 / 29$ & 1.00 (reference) & \\
\hline (CA)19/non-19 & $91 / 84$ & $0.72(0.40-1.28)$ & 0.259 & $57 / 52$ & $0.69(0.35-1.35)$ & 0.279 \\
\hline (CA)non-19/non-19 & $110 / 99$ & $0.70(0.40-1.23)$ & 0.216 & $59 / 67$ & $0.86(0.45-1.66)$ & 0.655 \\
\hline \multicolumn{7}{|l|}{ Group 2} \\
\hline$<38$ repeats & $78 / 52$ & $0.48(0.28-0.81)$ & 0.007 & $45 / 42$ & $0.74(0.40-1.37)$ & 0.339 \\
\hline 38 repeats & $40 / 56$ & 1.00 (reference) & & $36 / 45$ & 1.00 (reference) & \\
\hline$>38$ repeats & $111 / 111$ & $0.71(0.44-1.16)$ & 0.173 & $57 / 61$ & $0.85(0.48-1.51)$ & 0.585 \\
\hline
\end{tabular}

adjusted for age. 
Table 5. Association between (CA)19 repeat polymorphism and clinicopathologic characteristics of CRC.

\begin{tabular}{|c|c|c|c|c|}
\hline \multirow{2}{*}{$\begin{array}{l}\text { Clinical characteristics } \\
\text { n (\%) }\end{array}$} & \multicolumn{3}{|c|}{ (CA)19 repeat genotype $(n=367)$} & \multirow[b]{2}{*}{ p-value ${ }^{a}$} \\
\hline & $\begin{array}{l}(\mathrm{CA}) \\
19 / 19\end{array}$ & $\begin{array}{c}\text { (CA) } \\
19 / \text { non-19 }\end{array}$ & $\begin{array}{c}(\mathrm{CA}) \\
\text { non-19/non-19 }\end{array}$ & \\
\hline Sex & & & & 0.689 \\
\hline Female & $29(44.6)$ & $52(38.2)$ & $67(40.4)$ & \\
\hline Male & $36(55.4)$ & $84(61.8)$ & $99(59.6)$ & \\
\hline Tumor location & & & & 0.992 \\
\hline Colon & $21(32.3)$ & $45(33.1)$ & $54(32.5)$ & \\
\hline Rectum & $44(67.7)$ & $91(66.9)$ & $112(67.5)$ & \\
\hline Dukes stage & & & & 0.768 \\
\hline $\mathrm{A}+\mathrm{B}$ & $40(61.5)$ & $77(56.6)$ & $94(56.6)$ & \\
\hline $\mathrm{C}+\mathrm{D}$ & $25(38.5)$ & $59(43.4)$ & $72(43.4)$ & \\
\hline Degree of differentiation & & & & 0.244 \\
\hline High/High-moderate & $12(18.5)$ & $38(27.9)$ & $44(26.5)$ & \\
\hline Moderate & $36(55.4)$ & $77(56.6)$ & $97(58.4)$ & \\
\hline Moderate-low/Low & $17(26.1)$ & $21(15.5)$ & $25(15.1)$ & \\
\hline
\end{tabular}

Table 6. Association between the sum of CA repeats in both alleles and clinicopathologic characteristics of CRC.

\begin{tabular}{|c|c|c|c|}
\hline \multirow{2}{*}{$\begin{array}{l}\text { Clinical characteristics } \\
\text { n (\%) }\end{array}$} & \multicolumn{2}{|c|}{ the sum of CA repeats $(n=367)$} & \multirow{2}{*}{ p-value } \\
\hline & $\mathrm{CA} \leq 38$ repeats & $\mathrm{CA}>38$ repeats & \\
\hline Sex & & & 0.075 \\
\hline Female & $87(44.6)$ & $61(35.5)$ & \\
\hline Male & $108(55.4)$ & $111(64.5)$ & \\
\hline Tumor location & & & 0.782 \\
\hline Colon & $65(33.3)$ & $55(32.0)$ & \\
\hline Rectum & $130(66.7)$ & $117(68.0)$ & \\
\hline Dukes stage & & & 0.814 \\
\hline $\mathrm{A}+\mathrm{B}$ & $111(56.9)$ & $100(58.1)$ & \\
\hline $\mathrm{C}+\mathrm{D}$ & $84(43.1)$ & $72(41.9)$ & \\
\hline Degree of differentiation & & & 0.044 \\
\hline High/High-moderate & $41(21.0)$ & $53(30.8)$ & \\
\hline Moderate & $114(58.5)$ & $96(55.8)$ & \\
\hline Moderate-low/Low & $40(20.5)$ & $23(13.4)$ & \\
\hline
\end{tabular}

abased on chi-square test.

Table 7. Association between IGF1 CA genotype and circulating level of IGF1 in controls.

\begin{tabular}{lccc}
\hline \multirow{2}{*}{ IGF1 CA genotype } & \multicolumn{3}{c}{ Circulating level of IGF1 } \\
\cline { 2 - 4 } & Overall & Male & Female \\
\hline CA $\leq 38$ repeats & $129.02 \pm 47.21$ & $133.30 \pm 44.82$ & $122.25 \pm 50.33$ \\
CA $>38$ repeats & $137.56 \pm 46.39$ & $144.58 \pm 45.76$ & $123.38 \pm 44.80$ \\
p-value $^{\mathrm{a}}$ & 0.098 & 0.071 & 0.899 \\
Presence of (CA)19 & $130.84 \pm 43.19$ & $136.98 \pm 40.88$ & $120.75 \pm 45.26$ \\
Absence of $(\mathrm{CA}) 19$ & $135.18 \pm 50.92$ & $140.44 \pm 50.13$ & $125.17 \pm 51.38$ \\
p-value $^{\mathrm{a}}$ & 0.399 & 0.581 & 0.616 \\
\hline
\end{tabular}

abased on independent sample t-test. influences CRC risk by itself or by its regulation on circulating level of IGF1, which needs to be explored further. In addition, our results revealed that patients carrying $\leq 38 \mathrm{CA}$ repeats tended to have poor differentiation of CRC. This may be one of evidences for clinicians to estimate the prognosis of CRC patients. Nevertheless, this result should be explained cautiously due to the limited number of patients in our study. Greater numbers of patients are needed to deeply investigate the relationship between CA repeat polymorphism and clinicopathological features of CRC.

Moreover, it has been shown that the (CA)18/19 genotype was significantly related to the decreased risk of CRC in the native Chinese population in our study, nevertheless, it suggested that (CA)21 repeat allele was associated with reduced CRC risk in a Singapore Chinese population (CA21/21 genotype versus other genotype, $\mathrm{OR}=0.48 ; 95 \%$ $\mathrm{CI}=0.28-0.84)[11]$.

The most common allele was (CA)19 repeat allele in this native Chinese population, which was consistent with a Singapore Chinese [11], German [22], African American and White population [23], but the range of CA repeats was variable in different populations. Most studies focused on the role of (CA)19 repeat allele in CRC risk. Some studies obtained the same conclusion as we gained that there was no association between (CA)19 repeat polymorphism and CRC risk [11,20,22], so were another two meta-analyses [26, 27]. Nevertheless, some studies indicated a significant association between CRC risk and (CA)19 repeat polymorphism [21, 23, 24 , which was inconsistent with our finding. Morimoto et al. [21] demonstrated that other genotype was moderately related to CRC risk compared with (CA)19/19 genotype $(\mathrm{OR}=1.3 ; 95 \% \mathrm{CI}=1.0-1.6)$, while this association was limited to females after stratification by sex. Similarly, Keku et al. [23] and Simons et al. [24] also confirmed the significant association between (CA)19 repeat polymorphism and CRC risk. Therefore, there is no consensus on the association between (CA) 19 repeat allele and CRC risk. The inconsistency of these results may attribute to some possible factors: 1) the frequency distribution of $\mathrm{CA}$ alleles and the range of CA repeat vary in different populations; 2) the sample size is diverse in different studies; and 3) the confounding factors adjusted in various studies are not exactly the same. In addition, our results have shown no association between (CA)19 repeat polymorphism and circulating level of IGF1 in controls, which was similar to the conclusion of a metaanalysis [6].

Some limitations should be pointed out in our study. First of all, circulating level of IGF1 was determined only at single time point, which may not actually reflect long term level of IGF1 as it could be influenced by many factors as widely known. Then, the recruited participants were all Han Chinese, and the power to explain results was finite due to the limited sample size, greater number of populations and comparison with other ethnicities in China are needed in further studies. Moreover, CRC is a complicated disease as carcinogen- 
esis may be a result of a combination of environmental and genetic factors, we cannot adjust for all confounding factors when the association between CA repeat polymorphism and CRC risk is evaluated.

In conclusion, the present study shows that individuals carrying $<38$ CA repeats but not $>38$ CA repeats is associated with decreased risk of $\mathrm{CRC}$ in comparison with individuals carrying 38 CA repeats, especially in males after stratification by sex. Our findings support the possible role of CA repeat polymorphism in CRC risk.

Acknowledgements: We sincerely thank all participants for providing blood specimen. The study was financially supported by A Key Project of Tianjin Bureau of Public Health (No. 12KG104).

\section{References}

[1] BRAY F, FERLAY J, SOERJOMATARAM I, SIEGEL RL, TORRE LA et al. Global cancer statistics 2018: GLOBOCAN estimates of incidence and mortality worldwide for 36 cancers in 185 countries. CA Cancer J Clin 2018; 68: 394-424. https://doi.org/10.3322/caac. 21492

[2] XI L, ZHU J, ZHANG H, MUKTIALI M, XU C et al. Epidemiological Trends in Gastrointestinal Cancers in China: An Ecological Study. Dig Dis Sci 2019; 64: 532-543. https://doi. org/10.1007/s10620-018-5335-6

[3] STEWART CE, ROTWEIN P. Growth, differentiation, and survival: multiple physiological functions for insulin-like growth factors. Physiol Rev 1996; 76: 1005-1026. https://doi. org/10.1152/physrev.1996.76.4.1005

[4] LAHM H, SUARDET L, LAURENT PL, FISCHER JR, CEYHAN A et al. Growth regulation and co-stimulation of human colorectal cancer cell lines by insulin-like growth factor I, II and transforming growth factor alpha. Br J Cancer 1992; 65: 341-346. https://doi.org/10.1038/bjc.1992.69

[5] REMACLE-BONNET MM, GARROUSTE FL, HELLER S, ANDRE F, MARVALDI JL et al. Insulin-like growth factor-I protects colon cancer cells from death factor-induced apoptosis by potentiating tumor necrosis factor alpha-induced mitogen-activated protein kinase and nuclear factor kappaB signaling pathways. Cancer Res 2000; 60: 2007-2017.

[6] CHEN W, WANG S, TIAN T, BAI J, HU Z et al. Phenotypes and genotypes of insulin-like growth factor 1, IGF-binding protein-3 and cancer risk: evidence from 96 studies. Eur J Hum Genet 2009; 17: 1668-1675. https://doi.org/10.1038/ ejhg.2009.86

[7] HOLMES MD, POLLAK MN, HANKINSON SE. Lifestyle correlates of plasma insulin-like growth factor I and insulinlike growth factor binding protein 3 concentrations. Cancer Epidemiol Biomarkers Prev 2002; 11: 862-867.

[8] DELELLIS K, RINALDI S, KAAKS RJ, KOLONEL LN, HENDERSON B et al. Dietary and lifestyle correlates of plasma insulin-like growth factor-I (IGF-I) and IGF binding protein-3 (IGFBP-3): the multiethnic cohort. Cancer Epidemiol Biomarkers Prev 2004; 13: 1444-1451.
[9] HARRELA M, KOISTINEN H, KAPRIO J, LEHTOVIRTA $\mathrm{M}$, TUOMILEHTO J et al. Genetic and environmental components of interindividual variation in circulating levels of IGF-I, IGF-II, IGFBP-1, and IGFBP-3. J Clin Invest 1996; 98: 2612-2615. https://doi.org/10.1172/JCI119081

[10] ROSEN CJ, KURLAND ES, VEREAULT D, ADLER RA, RACKOFF PJ et al. Association between serum insulin growth factor-I (IGF-I) and a simple sequence repeat in IGFI gene: implications for genetic studies of bone mineral density. J Clin Endocrinol Metab 1998; 83: 2286-2290. https:// doi.org/10.1210/jcem.83.7.4964

[11] WONG HL, DELELLIS K, PROBST-HENSCH N, KOH WP, VAN DEN BERG D et al. A new single nucleotide polymorphism in the insulin-like growth factor I regulatory region associates with colorectal cancer risk in singapore chinese. Cancer Epidemiol Biomarkers Prev 2005; 14: 144-151.

[12] SARKISSYAN M, MISHRA DK, WU Y, SHANG X, SARKISSYAN $S$ et al. IGF gene polymorphisms and breast cancer in African-American and Hispanic women. Int J Oncol 2011; 38: 1663-1673. https://doi.org/10.3892/ijo.2011.990

[13] JAVADI M, HEMATTI S, TAVASSOLI M. Polymorphic CA repeat length in insulin-like growth factor 1 and risk of breast cancer in Iranian women. Med Oncol 2012; 29: 516520. https://doi.org/10.1007/s12032-011-9936-6

[14] WEN W, GAO YT, SHU XO, YU H, CAI Q et al. Insulin-like growth factor-I gene polymorphism and breast cancer risk in Chinese women. Int J Cancer 2005; 113: 307-311. https:// doi.org/10.1002/ijc.20571

[15] SLATTERY ML, SWEENEY C, WOLFF R, HERRICK J, BAUMGARTNER $\mathrm{K}$ et al. Genetic variation in IGF1, IGFBP3, IRS1, IRS2 and risk of breast cancer in women living in Southwestern United States. Breast Cancer Res Treat 2007; 104: 197-209. https://doi.org/10.1007/s10549-0069403-9

[16] SCHILDKRAUT JM, DEMARK-WAHNEFRIED W, WENHAM RM, GRUBBER J, JEFFREYS AS et al. IGF1 (CA)19 repeat and IGFBP3 -202 A/C genotypes and the risk of prostate cancer in Black and White men. Cancer Epidemiol Biomarkers Prev 2005; 14: 403-408. https://doi.org/10.1158/10559965.EPI-04-0426

[17] FRIEDRICHSEN DM, HAWLEY S, SHU J, HUMPHREY M, SABACAN L et al. IGF-I and IGFBP-3 polymorphisms and risk of prostate cancer. Prostate 2005; 65: 44-51. https://doi. org/10.1002/pros.20259

[18] HERNANDEZ W, GRENADE C, SANTOS ER, BONILLA C, AHAGHOTU C et al. IGF-1 and IGFBP-3 gene variants influence on serum levels and prostate cancer risk in African-Americans. Carcinogenesis 2007; 28: 2154-2159. https://doi.org/10.1093/carcin/bgm190

[19] LI L, CICEK MS, CASEY G, WITTE JS. No association between genetic polymorphisms in IGF-I and IGFBP-3 and prostate cancer. Cancer Epidemiol Biomarkers Prev 2004; 13: 497-498.

[20] SLATTERY ML, SAMOWITZ W, CURTIN K, MA KN, HOFFMAN $\mathrm{M}$ et al. Associations among IRS1, IRS2, IGF1, and IGFBP3 genetic polymorphisms and colorectal cancer. Cancer Epidemiol Biomarkers Prev 2004; 13: 1206-1214. 
[21] MORIMOTO LM, NEWCOMB PA, WHITE E, BIGLER J, POTTER JD. Insulin-like growth factor polymorphisms and colorectal cancer risk. Cancer Epidemiol Biomarkers Prev 2005; 14: 1204-1211.

[22] PECHLIVANIS S, WAGNER K, CHANG-CLAUDE J, HOFFMEISTER M, BRENNER $\mathrm{H}$ et al. Polymorphisms in the insulin like growth factor 1 and IGF binding protein 3 genes and risk of colorectal cancer. Cancer Detect Prev 2007; 31: 408-416. https://doi.org/10.1016/j.cdp.2007.10.001

[23] KEKU TO, VIDAL A, OLIVER S, HOYO C, HALL IJ et al. Genetic variants in IGF-I, IGF-II, IGFBP-3, and adiponectin genes and colon cancer risk in African Americans and Whites. Cancer Causes Control 2012; 23: 1127-1138. https:// doi.org/10.1007/s10552-012-9981-2
[24] SIMONS CC, SCHOUTEN LJ, GODSCHALK RW, VAN ENGELAND M, VAN DEN BRANDT PA et al. Genetic Variants in the Insulin-like Growth Factor Pathway and Colorectal Cancer Risk in the Netherlands Cohort Study. Sci Rep 2015; 5: 14126. https://doi.org/10.1038/srep14126

[25] AL-AJMI K, GANGULY SS, AL-AJMI A, MANDHARI ZA, AL-MOUNDHRI M. Insulin-like growth factor 1 gene polymorphism and breast cancer risk among arab omani women: a case-control study. Breast Cancer (Auckl) 2012; 6: 103-112. https://doi.org/10.4137/BCBCR.S9784

[26] QUAN H, TANG H, FANG L, BI J, LIU Y et al. IGF1(CA)19 and IGFBP-3-202A/C gene polymorphism and cancer risk: a meta-analysis. Cell Biochem Biophys 2014; 69: 169-178. https://doi.org/10.1007/s12013-013-9784-4

[27] GUO Q, SHEN F, ZHANG C, YANG X, ZHU HC et al. IGF-I CA19 repeat polymorphisms and cancer risk: a meta-analysis. Int J Clin Exp Med 2015; 8: 20596-20602. 